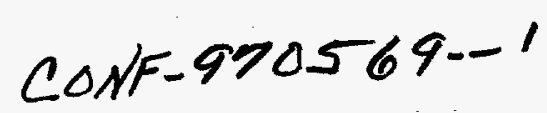

\title{
Mini Ball Grid Array (mBGA) Assembly on MCM-L Boards
}

by

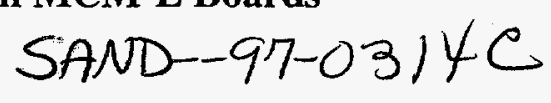

\author{
Rajen Chanchani, Keith Treece and Paul Dressendorfer \\ Sandia National Laboratories \\ Mail Stop 1073, Department 1277 \\ Albuquerque, New Mexico 87185 \\ Tel: (505) 844-3482 \\ Fax: (505) 844-8480 \\ email: chanchr@sandia.gov
}

\begin{abstract}
Sandia National Laboratories has developed a chip scale packaging technology called mini Ball Grid Array (mBGA). The mBGA is a flip chip die, obtained by redistributing peripheral pads in existing dies to an area array of pads 10 mils or larger in diameter with a minimum pitch of 20 mils. The peripheral pads are redistributed to area array pads using two polyimide dielectric and two metal conductor layers. $\mathrm{mBGA}$ can be closely tiled together on a substrate to yield a very high circuit density. In an earlier report, we presented the results on the reliability and thermal performance of $\mathrm{mBGA}$ on silicon and ceramic substrates. In this report, we present an mBGA cost analysis, improvements in the mBGA bump adhesion, and reliability and thermal performance of $\mathrm{mBGA}$ assemblies on FR-4 boards.
\end{abstract}

\section{Introduction}

Two years ago, Sandia National Laboratories first reported $^{1,2}$ a chip scale packaging technology, called mini Ball Grid Array (mBGA). The mBGA, as shown in Figure 1 , is a flip chip die, obtained by redistributing peripheral pads in existing dies to an area array of pads 10 mils or larger in diameter with a minimum pitch of 20 mils. This technology uses dies originally designed for wire bonding. The large pad size and pitch of the mBGA facilitates testing for "known good die" and cost-effective assembly using standard surface mount equipment and processes.

In $\mathrm{mBGA}$, peripheral pads on a silicon die are redistributed to an area array using two polyimide or Benzocyclobutene (BCB) dielectric layers by post processing silicon wafers. Standard photo-mask, etch, sputter and plate wafer processes are used. Wafer processing has been done at APTOS Corp. (Milpitas, CA) and GE Corp. (Schenectady, NY). Micrographs of a mBGA die are shown in Figure 2. To date, ten different die types, listed in Table 1 , have been processed into mBGAs. A 30 mils array pitch and 2 mil lines/spaces/vias were used for all die except the ASICs. ASIC dies which have about 300 peripheral pads on 5 mils pitch required 20 mils array pitch. Reducing the array pitch below 20 mils would further burden the followon activities such as die testing, die-to-substrate attachment and the substrate routing. For all ASIC dies used by Sandia, an area pad array of 20 mils pitch or higher was found to be adequate to allow redistribution of all peripheral pads within the die area. The terminations on the I/O pads investigated are either gold, $40 / 60$ or $95 / 5$ $\mathrm{Pb} / \mathrm{Sn}$ solders. Thus, mBGAs can be either solder or conductive adhesive attached to the substrate. Since the pad size, pitch and metallurgy of the mBGA dies are similar to other surface mount components, its testing and alignment/attachment processes are also similar. Large pad size (10 mils or larger) and pitch ( 20 mils or larger) of $\mathrm{mBGA}$ allows us to use test sockets or carriers with mating pads as described elsewhere ${ }^{3,2}$. mBGAs can be fully tested for functionality, and thus can be used as known good dies in a MCM.

In past reports ${ }^{1.2}$, we have shown that mBGA dies can be reliably used on silicon MCM-D substrates without a need for underfill encapsulant. However, in recent years, there is a thrust to develop low cost, high circuit density electronics using MCM-L technology. mBGA package is a suitable choice for such an application because of its lower cost and its potential to provide a high circuit density. But there are several concerns in assembling flip chip bare dies, including mBGA, on MCM-L boards made of low cost FR4 materials. The major concern is the higher thermal expansion mismatch between the silicon die and FR-4 board materials. Higher thermal expansion mismatch will increase the shear strain in the flip chip solder joints, which could eventually fatigue crack during thermal cycling. This problem can be overcome by using tall flip chip joints or as per the reports from $\mathrm{IBM}^{3}$ by using thermal expansion matched underfill encapsulants. The other concerns are the heat dissipation, moisture absorption and routability of FR-4 boards.

The overall objectives of this study are to present the results of mBGA cost modelling, to improve and test the mBGA bump adhesion to polyimide and $\mathrm{BCB}$ dielectric materials, to investigate the feasibility of assembling mBGA on FR-4 boards, and to characterize the reliability and thermal performance of this assembly.

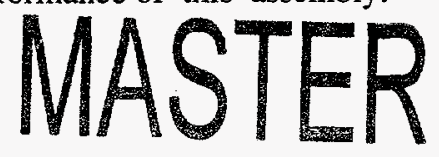

MCM-L Test Vehicles

Experimental 


\section{DISCLAIMER}

This report was prepared as an account of work sponsored by an agency of the United States Government. Neither the United States Government nor any agency thereof, nor any of their employees, make any warranty, express or implied, or assumes any legal liability or responsibility for the accuracy, completeness, or usefulness of any information, apparatus, product, or process disclosed, or represents that its use would not infringe privately owned rights. Reference herein to any specific commercial product, process, or service by trade name, trademark, manufacturer, or otherwise does not necessarily constitute or imply its endorsement, recommendation, or favoring by the United States Government or any agency thereof. The views and opinions of authors expressed herein do not necessar. ily state or reflect those of the United States Government or any agency thereof. 


\section{DISCLAMMER}

Portions of this document may be illegible in electronic image products. Images are produced from the best available original document. 
We have built two MCM-L test vehicles using mBGA. The description of the board material, assembly process used and the test vehicle fabricated are described below.

Board Material: All FR-4 boards were fabricated at HADCO, Watsonville, California, using Polyclad FR-4 Tetra II plus \#370G material having a glass transition temperature of $180^{\circ} \mathrm{C}$ and dielectric constant of 3.9 . According to the vendor specification, this material has a thermal expansion of $14 \mathrm{ppm} /{ }^{\circ} \mathrm{C}$ in the $\mathrm{X} \& \mathrm{Y}$ planes and $45 \mathrm{ppm} /{ }^{\circ} \mathrm{C}$ in $\mathrm{Z}$ axis. The boards were 4 layered and 33 mils thick. The design rules used for physical layout of the board are 2 mils minimum lines and spaces, and 8 mil drilled holes with 20 mil cover pads. The boards using these design rules were developmental products from HADCO.

In order to investigate the effect of flip chip joint height on the thermal shock reliability, we assembled two different joint heights by using boards with two pad finishes, Au flash or 6 mil high solder deposited using a Precision Pad Technology (PPT) process. In the PPT process ${ }^{4}$, a trademark process of MASTEK Inc., California, boards with 3 mil solder mask having about $1.5 \mathrm{x}$ the pad area opening are used. Solder paste is screen printed in the opening area and reflowed with the screen still in place. This process gives a solder deposit that is 6 mils high and rather flat with a screen imprint.

Assembly Process: Two test vehicle types were assembled on FR-4 boards using mBGAs with polyimide dielectric and $60 / 40 \mathrm{Sn} / \mathrm{Pb}$ solder bumps. The assembly was done in the following steps.

1. mBGA dies were electrically tested in a socket and visually inspected for any defects such as dielectric delamination and missing or incomplete bumps. The boards were only visually inspected for any discontinuity in the circuit pattern, and the solder deposit quality.

2. Inspected mBGA dies were coined by $1 \mathrm{mil}$ at $45^{\circ} \mathrm{C}$.

3. Alpha 5003 flux was applied on the board.

4. mBGA dies were aligned to the substrate using a vision system.

5. Solder was reflowed at about $220^{\circ} \mathrm{C}$ for about a minute.

6. The assembly was washed and rinsed in IONOX solvent and dried in ACCEL Cleaning Equipment and then soaked in isopropyl alcohol for 1.5 hours.

7. The cleaned assembly was underfilled with Hysol 4511 or 4520 .

No major problems were encountered during the prototype fabrication and assembly of mBGA dies on FR-4. After assembly, as shown in Figure 3, we obtained a 3 mil high flip chip joint in the assembly on FR-4 without PPT solder and 7 mil high joint in the assembly with PPT solder. The above assembly process was designed to provide fabrication of clean and reliable prototype assemblies, but was not optimized for volume production.
Description of Test vehicles: Test Vehicle 1 - As seen in Figure 4, this test vehicle consist of four daisy chain mBGA dies assembled on a 1.8" square board. Three dies (LCA) are 0.410 " mil square and one die (X4010) is 0.554" x 0.563 " with a total of 988 flip chip joints. This vehicle was used for the joint reliability tests in thermal shock environment.

Test Vehicle 2 - As seen in Figure 4, this test vehicle also consist of four dies on 1.8" square board. Three dies are Sandia's ATC03 assembly test chips ${ }^{5}$ and the fourth die is a $\mathrm{X} 4010$ daisy chain test die. These four dies have a total of 938 I/Os. ATC03 is one of the dies from a family of Sandia's Assembly Test Chips. It contains temperature and strain sensors, triple tracks for corrosion studies, and heaters. Each die is $0.635 \mathrm{~cm}$ ( 0.25 ") square. To simulate a larger die, we used an ATC03 quad, $1.27 \mathrm{~cm}(0.5$ ") square, obtained by dicing a cluster of four dies from a wafer. ATCO3 quad was used to study the heat dissipation characteristics of mBGA dies with and without heatsink.

Both test vehicle boards were of the same size (1.8" square) and had a common 172 pad I/O footprint so that a single test fixture could be used for electrical tests.

\section{Test Procedures}

mBGA Bump Adhesion Tests: mBGA bump adhesion tests were done by ball shear method using Dage Precima Ball Shear Tester, as shown in Figure 5. The shear tool, adjusted to the height of 12 microns from the surface of the substrate, was used in shearing the bumped solder ball on mBGA. After shearing, the shear force and the mode of failure were noted. Two failure modes, as also shown in Figure 5, were observed, namely solder shear and bump lift-off. In solder shear, the tool plastically shears the solder, whereas in bump lift-off, the whole bump delaminates at the dielectric-bump interface.

Thermal Shock Reliability: The assembled parts were thermal shocked, air to air at two temperature ranges. The first set of data were taken in the range of $0^{\circ}$ to $100^{\circ} \mathrm{C}$ for 2000 cycles. This test simulates the use environment in low cost consumer goods application. The second set of data were taken from $-55^{\circ}$ to $125^{\circ} \mathrm{C}$ for 500 cycles. This test simulates the high performance environment, as recommended in MIL-STD 883. In each case, the daisy chain dies were electrically tested for opens every 20 cycles for first 100 cycles and every 100 cycles thereafter.

Heat Dissipation Characterization Tests: The Test Vehicle 2 was powered through the heaters located in three ATC03 dies. Power input in the increments of 1 watt/module or 0.33 watts/ATC03 quad die was provided and the average temperature was noted from the 8 temperature sensing diodes on ATC03 quad. A twenty minutes delay after changes in the power input was allowed before temperature readings were taken so that the module would reach steady state. Temperature measurements were taken at the power 
increments until a die temperature rise of $60^{\circ} \mathrm{C}$ or the current carrying capacity of the test fixture $(10$ watts/module) was reached. Die temperature rise of $60^{\circ} \mathrm{C}$ at our test lab ambient temperature of $25^{\circ} \mathrm{C}$, will make the die temperature $85^{\circ} \mathrm{C}$. In our results, we have reported the average of 8 temperature sensor diodes.

\section{Cost Analysis}

\section{Results and Discussion}

Since mBGA is processed on wafer scale, its fabrication cost is competitive with other mature packaging technologies. A comprehensive cost analysis ${ }^{6}$ was done jointly by Sematech and Sandia National Laboratories to compare the relative costs of Chip Scale Packages to conventional surface mount technology using a Cost Resource Model developed by Sematech. In Figure 6a, the $\mathrm{mBGA}$ package cost (per $\mathrm{HO}$ pin) as a function of production volume for a high pin count device (256 pin ASIC) is compared to the cost of Plastic Quad Flat Pack (PQFP) and Plastic Ball Grid Array (PBGA) packages. mBGA cost is projected to be lower than the mature packaging technologies for production volumes greater than 1 million/month. Similar cost comparison for mBGA and Thin Small Outline Package (TSOP) for a low pin count ( 26 pin memory device) is shown in Figure $6 \mathrm{~b}$. The cost of mBGA is about the same as TSOP for the production volumes of 10,000 to 10 million per month.

\section{mBGA Bump Adhesion Tests}

In $\mathrm{mBGA}$, the strength of bump adhesion to the dielectric is critical, especially under higher shear strain conditions encountered in mBGA assembly on FR-4 boards, which have higher thermal expansion coefficient of $14 \mathrm{ppm} /{ }^{\circ} \mathrm{C}$ as compared to $3 \mathrm{ppm} /{ }^{\circ} \mathrm{C}$ for $\mathrm{mBGA}$. We have investigated the following two improvements in the $\mathrm{mBGA}$ fabrication to improve the bump adhesion.

1. In initial mBGA batches, the bump adhesion to the polyimide was low. Improvement was obtained by adding a step involving plasma etching of the surface of the top polyimide layer to make the surface rougher prior to metallization.

2. $\mathrm{BCB}$ dielectric material potentially provides better planarization and absorbs less moisture. In addition, $\mathrm{BCB}$ adheres to copper without the need for adhesion metal layers as in the case of polyimide. Thus BCB will require fewer process steps and potentially will cost less to process. We have fabricated an initial batch of mBGAs with photosensitive $\mathrm{BCB}$ dielectric using the standard process described elsewhere? To date, bump adhesion tests have been done with this batch of parts.

Bump Adhesion to Poyimide Dielectric: Bump adhesion on polyimide deposited with the old process and with the modified process are shown in Table 2. The modified process involved additional plasma etching of the top dielectric layer. Shear strength is improved by over $33 \%$ with the modified polyimide processing. With the older polyimide process, the failure mechanism during the shear test was bump lift-off indicating a poor bump adhesion to the polyimide process. With the modified process, the failure mechanism was consistently solder shearing indicating stronger bump adhesion.

Bump Adhesion to $\mathrm{BCB}$ Dielectric: The preliminary test results for bump adhesion to $\mathrm{BCB}$ dielectric is also shown in comparison to polyimide in Table 2. Bump adhesion strength on $\mathrm{BCB}$ dielectric is not significantly different than that on the polyimide deposited with the modified process. Also, the failure mechanism was solder shearing, indicating a stronger bump adhesion as in the case with modified polyimide process.

\section{Thermal Shock Reliability}

The main reliability concern in mBGA assembly on FR-4 is thermal fatigue cracking of flip chip solder joints caused by thermal expansion mismatch between the mating materials during thermal shock cycles. In our earlier work, we determined that $\mathrm{mBGA}$ on silicon and alumina ceramic substrates without underfill survived 1000 cycles of $0^{\circ}$ to $100^{\circ} \mathrm{C}$ thermal shock. In this study, we investigated the reliability of $\mathrm{mBGA}$ assembly on FR-4 under $0^{\circ}$ to $100^{\circ} \mathrm{C}$ and $-55^{\circ}$ to $125^{\circ} \mathrm{C}$ thermal shock cycling conditions. mBGA assemblies with and without underfill encapsulation and flip chip joint heights of 3 mils and 7 mils were used. All modules used in $0^{\circ}$ to $100^{\circ} \mathrm{C}$ thermal shock cycle tests had mBGAs fabricated with old polyimide process. In the $55^{\circ}$ to $125^{\circ} \mathrm{C}$ thermal shock cycle tests, we have used modules containing mBGAs processed with both old and modified polyimide processes.

$0^{\circ}$ to $100^{\circ} \mathrm{C}$ Thermal Shock: The results for $\mathrm{mBGA}$ assembly on FR-4 are shown in Table 3. For comparison, we have also shown the results from our earlier work on mBGA assemblies on silicon MCM-D substrates. mBGA on silicon substrate survived 1000 cycles of testing. These parts were not underfilled and the flip chip joint height was 4.5 mils. mBGA assembly on FR-4 without underfill failed within first 10 cycles for flip chip joint heights of 3 mils, and failed within 40 cycles for flip chip joint height of 7 mils. All five FR- 4 modules (total of $20 \mathrm{mBGA}$ dies) with Hysol 4511 underfill and one FR-4 module (total of 4 mBGA dies) with Hysol 4520 underfill survived all 2000 cycles without a joint failure. No significant difference in the reliability of modules with underfill between the joint heights of 3 mils and 7 mils was observed.

$-55^{\circ}$ to $125^{\circ} \mathrm{C}$ Thermal Shock: The tests were done with three modules, all of which were underfilled with HYSOL 4511 and had joint height of 7 mils. Two of the modules had mBGA dies processed with older polyimide process and had lower bump adhesion strength. The third module had mBGAs that were fabricated with modified polyimide process and had stronger bump adhesion. The results are shown in Table 4. The mBGAs fabricated using old polyimide process failed within 500 cycles, whereas the mBGA fabricated using the modified polyimide process survived 500 cycles. The failed mBGAs probably 
delaminated at the bump-polyimide interface because of poor bump adhesion in these parts as reported in Table 2 . Currently we are doing a detailed failure analysis to determine the failure mechanisms.

The following points can be made about the reliability results.

1. The reliability of $\mathrm{mBGA}$ assembly on FR-4 with underfill will probably meet thermal shock requirements for most applications.

2. The results show that the mBGA assembly must be underfilled for joint heights of up to 7 mils. However, underfilled dies cannot be easily reworked. One main advantage of mBGA dies is that they can be fully tested for functionality in a socket before they are assembled. Thus they will not require rework unless the dies get damaged during assembly.

3. For applications requiring to pass $-55^{\circ}$ to $125^{\circ} \mathrm{C}$ thermal shock tests, our data indicate that the modified polyimide deposition process should be preferably used.

\section{Heat Dissipation Characterization Tests}

The purpose for these tests was to determine the maximum power that the module can withstand with and the type of the cooling scheme required. These factors directly affect module reliability and the overall system miniaturization. The thermal dissipation characteristics of $\mathrm{mBGA}$ assembly on FR-4 board was experimentally determined using Test Vehicle 2 with 7 mil joint height.

In the first set, the heat dissipation ability of mBGA assembly on FR-4 without and with HYSOL 4511 underfill was characterized under natural air-cooling conditions (without any heatsink or forced air augmentation). Figure 7 shows mBGA die temperature rise as a function of power input per ATC03 die (0.5" square) in the module. The module with underfill ran about $10^{\circ} \mathrm{C}$ cooler than the module without underfill at power input of 1.25 watts. This is expected because without any heatsink augmentation, the majority of the thermal path is through the joints and the substrate. Having Hysol 4511 underfill material of thermal conductivity $0.6 \mathrm{ppm} /{ }^{\circ} \mathrm{C}$ in the gap between the mBGA die and the substrate helps in the heat transfer from the die to the substrate.

In the second set of tests, we have compared the heat dissipation characteristics of $\mathrm{mBGA}$ assemblies with underfill under three cooling conditions, natural air-cooled (without heatsink), air-cooled heatsink ( with fan turned off), and air-cooled heatsink with fan on (forced air @ 1.2 cu. ft. per minute). The results, power (watts/die) versus the die temperature rise $\left({ }^{\circ} \mathrm{C}\right)$ is shown in Figure 8. Under natural air-cooled conditions, the die is capable of dissipating 1.25 watts, before the die temperature exceeds $85^{\circ} \mathrm{C}$. With heatsink, the maximum powers dissipated are 3.5 watts/die with fan-off and above 6 watts/die with fanon (forced-air cooling @ 1.2 cu. ft. min.). These heat dissipation values are for each ATC03 quad die (0.5" sq.). Since there are three ATC03 quads dies on the module, heat dissipation per module will be three times the above values. In Figure 9, we have compared the heat dissipation data of mBGA on FR-4 and on silicon. In the case of natural air-cooling, the difference between the FR-4 board and silicon substrate curves is the widest. This trend is expected because under natural air-cooling condition, the majority of thermal path is through the substrate. Since thermal conductivity of silicon substrate is $150 \mathrm{ppm} /{ }^{\circ} \mathrm{C}$ and that of FR-4 is less than 1 watt ${ }^{\circ} \mathrm{C}$, heat transfer through silicon is much better than through FR-4. The curves for two substrate materials converge when heatsink is used. In this case, the majority of the heat path is through the heatsink, so the relative effect of the differences in the thermal conductivity of the two substrate materials is substantially reduced.

\section{Conclusions}

mBGA, a minimally packaged die technology developed at Sandia, involves redistributing peripheral pads on silicon die to an area array of pads with 20 mils pitch or larger using two metal/dielectric layers. Using a cost model, we have determined that the mBGA packaging cost is comparable to that of the mature packages such as TSOP for low pin count dies and is significantly lower cost than PBGA and PQFP for high pin count $(>100)$ dies.

We have improved $\mathrm{I} / \mathrm{O}$ bump adhesion to top dielectric layer by modifying the polyimide surface treatment; alternately, using BCB dielectric material provided improved adhesion and process simplification.

We have tested mBGAs in MCM-L (FR-4) test vehicles, which were specifically designed and fabricated for determining the feasibility of using mBGAs in low cost assemblies and characterizing the flip chip joint reliability and heat dissipation ability of the technology. mBGA assemblies with underfill survived thermal shock tests involving 2000 cycles of $0^{\circ}$ to $100^{\circ} \mathrm{C}$ thermal shock and 500 cycles of $-55^{\circ}$ to $125^{\circ} \mathrm{C}$ thermal shock. mBGA die assembled on FR-4 is capable of dissipating 1.25 watts without any heatsink, 3.5 watts with naturally air-cooled heatsink and over 6 watts with forced air heatsink. These heat dissipation values are for our test configuration and allowing a die temperature rise of $60^{\circ} \mathrm{C}$.

\section{Acknowledgments}

The authors wish to acknowledge APTOS Corp. for fabricating the mBGA dies and silicon substrates, Texas Instruments for assembling the soldered modules, and Universal Instruments for underfilling the mBGA dies. Acknowledgments are also due to Gary Peterson, Richard Beegle, Patrick Candelaria, John Baca and Karen Helgeson of Sandia National Labs for their help in fabrication and testing of the parts. 
This work was performed at Sandia National Laboratories and supported by the U.S. Department of Energy under contract DE-AC04-94AL85000. Sandia is a multiprogram laboratory operated by Sandia Corporation, a Lockheed Martin Company, for the United States Department of Energy.

\section{References}

1. Chanchani, R, Treece, R. K. and Dressendorfer, P., "A New mini Ball Grid Array (mBGA) Multichip Module Technology," International Journal of Microcircuits and Electronic Packaging, Vol. 18, No. 3, pp185-192 (1995).

2. Chanchani, R, Treece, R. K. and Dressendorfer, P., "mini Ball Grid Array (mBGA) Technology," Proceedings of NEPCONWEST, Anaheim, CA, pp. 938-945 (1995).

3. Suryanarayana, D., Hsiao, R., Gall, T. P. and McCreary, J. M., "Enhancement of Flip-Chip Fatigue Life by Encapsulation," IEEE Transactions on
Components,Hybrids, and Manufacturing, Vol.14, No. 1, pp. 218-223 (1991).

4. Payne, B. and Holzman, D., "A Step in the Right Direction," Circuit Assembly, pp. 59-64, February, 1993.

5. Sweet, J. M., Tuck, M. R., Peterson, D. W. and Palmer, D. W., "Short and Long Loop Manufacturing Feedback Using a Multisensor Assembly Test Chip," IEEE Trans. On Components, Hybrids and Manufacturing Technology, Vol. 13, pp. 656-660 (1990).

6. Reber, C. A., Su, L. and Louis, M. D., "Cost Resource Modeling For Chip Scale Packaging", SEMATECH Report SETEC96-068, (1996).

7. Strandjord, A. J. G. et al, "Process Optimization and Systems Integration of a Copper/Photosensitive BCB MCM-D: Dielectric Processing, Metallization, Solder Bumping, Device Assembly and Testing," International Journal of Microcircuits and Electronic Packaging, Vol. 19, No. 3, pp. 261-280 (1996).

TABLE 1. mBGA Processed Die Types

\begin{tabular}{|c|c|c|c|}
\hline Die Type & Description & \# of Pads & Pad Pitch \\
\hline MT5C2568 & Micron Memory & 34 & $.030^{\prime \prime}$ \\
\hline PDSP16515 & Plessey DSP & 128 & $.030 "$ \\
\hline LCA100106 & LSI Logic ASIC & 275 & $.020^{\prime \prime}$ \\
\hline L8095 & ASIC & 298 & $.020^{\prime \prime}$ \\
\hline LCA & Daisy Chain Die** & 266 & $.020^{\prime \prime}$ \\
\hline SA3470 & Microcontroller* & 52 & $.030^{\prime \prime}$ \\
\hline X4010 & Daisy Chain Die** & 191 & $.030^{\prime \prime}$ \\
\hline ATC03Quad & Assembly Test Chip* & 224 & $.030^{* \prime}$ \\
\hline ATC04 & Assembly Test Chip* & 35 & $.030^{* \prime}$ \\
\hline
\end{tabular}

*Silicon dies designed and fabricated at Sandia, **Silicon dies fabricated at Sandia

TABLE 2. mBGA Bump Adhesion Strength

Die: LCA Daisy Chain Die

\begin{tabular}{|c|c|c|c|c|}
\hline Dielectric Material/Process & \# of Wafers & Avg. Shear Force & Avg. Std. Deviation & Failure Mechanism \\
\hline $\begin{array}{c}\text { Polyimide- old } \\
\text { process }\end{array}$ & 4 & $149 \mathrm{gm}$. force & 39 & Mostly lift-off \\
\hline $\begin{array}{c}\text { Polyimide - modified } \\
\text { Process }\end{array}$ & 4 & $206 \mathrm{gm}$. force & 12 & solder shear \\
\hline $\begin{array}{c}\mathrm{BCB}-\text { Recommended } \\
\text { process }\end{array}$ & 1 & $197 \mathrm{gm}$. force & 9 & solder shear \\
\hline
\end{tabular}


Table 3. Reliability Data For 0 to $100^{\circ} \mathrm{C}$, Air to Air, Thermal Shock Tests.

\begin{tabular}{|c|c|c|c|c|c|c|}
\hline Substrate & Joint Height & Underfill & \# of Modules & Total \# of Dies & Total \# of Joints & \# of Cycles survived \\
\hline Silicon $^{1.2}$ & 4.5 mils & no underfill & 5 & 5 & 955 & $1000+$ \\
\hline & & & & & & \\
\hline FR-4 & 3 mils & no underfill & 1 & 4 & 988 & $<10$ \\
\hline FR-4 & 7 mils & no underfill & 3 & 12 & 2964 & $<10$ to 40 \\
\hline & & & & & & \\
\hline FR-4 & 3 mils & HYSOL 4511 & 3 & 12 & 2964 & $2000+$ \\
\hline FR-4 & 7 mils & HYSOL 4511 & 2 & 8 & 1976 & $2000+$ \\
\hline FR-4 & 7 mils & HYSOL 4520 & 1 & 4 & 988 & $2000+$ \\
\hline
\end{tabular}

Table 4. Reliability Data For -55 to $+125^{\circ} \mathrm{C}$, Air to Air, Thermal Shock Tests.

\begin{tabular}{|c|c|c|c|c|c|c|c|}
\hline Substrate & $\begin{array}{c}\text { mBGA } \\
\text { Process }\end{array}$ & $\begin{array}{c}\text { Joint } \\
\text { Height }\end{array}$ & Underfill & $\begin{array}{c}\text { \# of } \\
\text { Modules }\end{array}$ & $\begin{array}{c}\text { Total \# } \\
\text { of Dies }\end{array}$ & $\begin{array}{c}\text { Total \# } \\
\text { of Joints }\end{array}$ & \# of Cycles survived \\
\hline FR-4 & $\begin{array}{c}\text { Polyimide - } \\
\text { old process }\end{array}$ & 7 mils & HYSOL 4511 & 2 & 8 & 1976 & $\begin{array}{c}5 \text { dies failed within } 500 \text { cycles } \\
1 \text { st die failed after } 300 \text { cycles }\end{array}$ \\
\hline FR-4 & $\begin{array}{c}\text { Polyimide - } \\
\text { modified process }\end{array}$ & 7 mils & HYSOL 4511 & 2 & 8 & 1976 & All dies survived $500+$ cycles \\
\hline
\end{tabular}

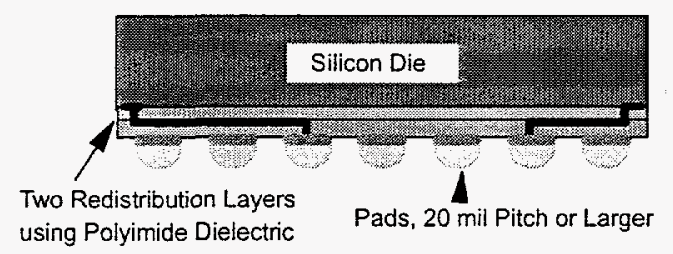

Figure 1. Schematic Drawing of mini Ball Grid Array (not to scale)
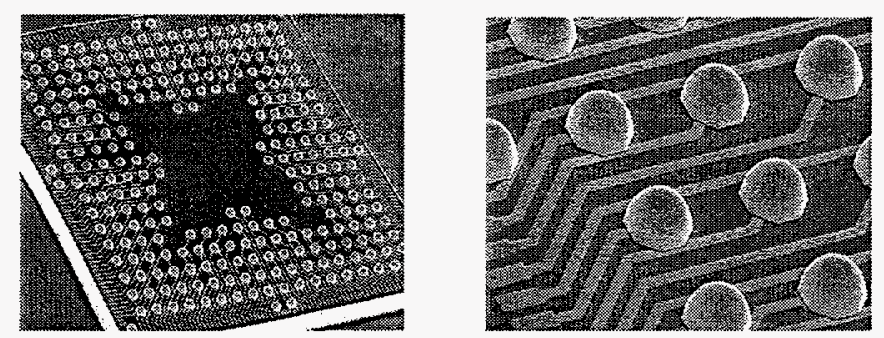

Figure 2. ASIC mBGA (die size $=0.410$ " square) with 275 pads on .020 " pitch and the magnified view of the solder bumps.

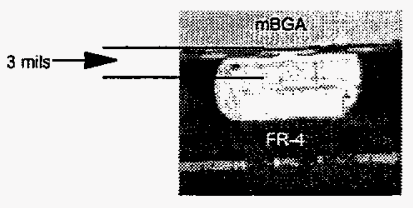

Joint on FR-4 Pad with Au Flash

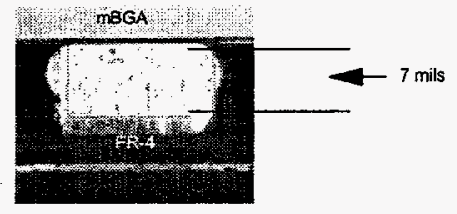

Joint on FR-4 Pad with 6 mil high PPT Solder

Figure 3. Optical micrographs of the mBGA solder joints on FR-4 (a) without PPT, and (b) with PPT. 


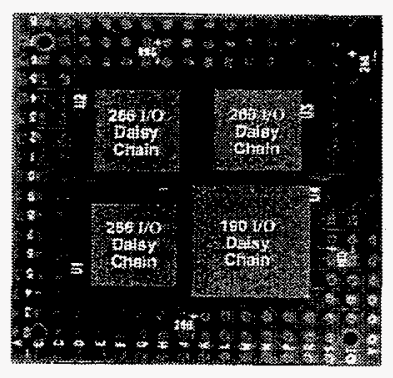

Test Vehicle \#1

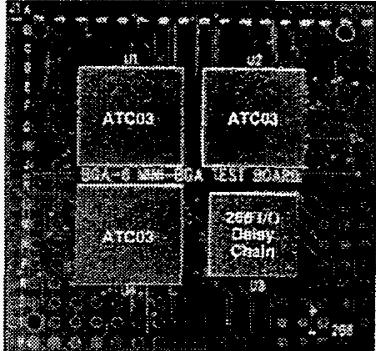

Test Vehicle \#2

Size: 1.8 square inches

Figure 4. Photographs of the assembled Test Vehicle \# 1 and Test Vehicle \# 2.

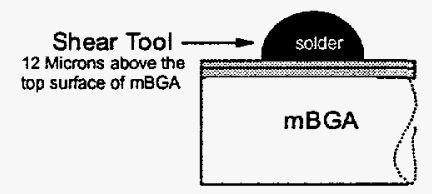

Bump Adhesion Test

(a)

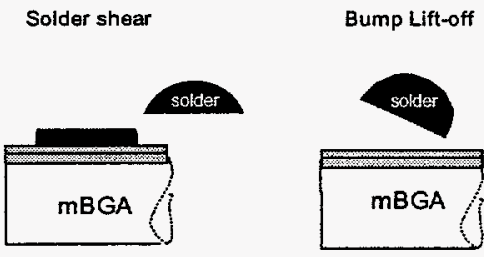

Failure Modes

(b)

Figure 5. Schematic drawings of (a) bump adhesion test conditions, and (b) the failure modes.

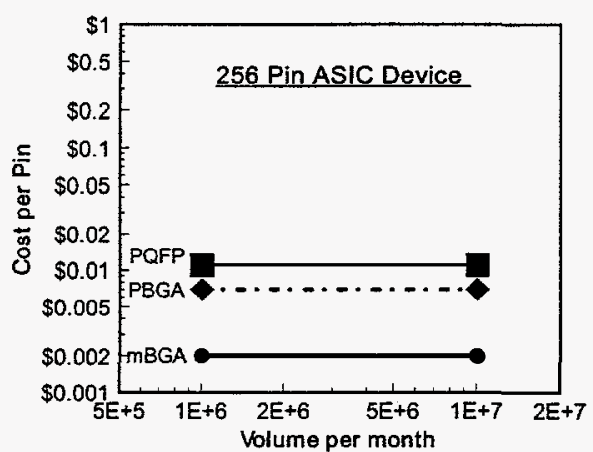

(a)

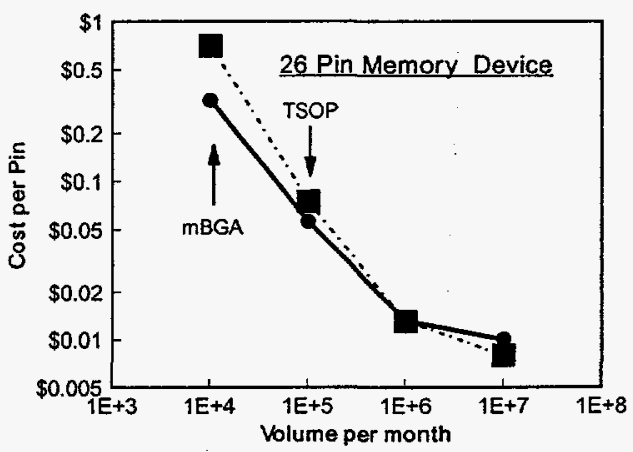

(b)

Figure 6. Cost of (a) mBGA as compared to PQFP and PBGA Packages for a 256 pin ASIC device, and (b) $\mathrm{mBGA}$ as compared to TSOP for a 26 pin memory device. 


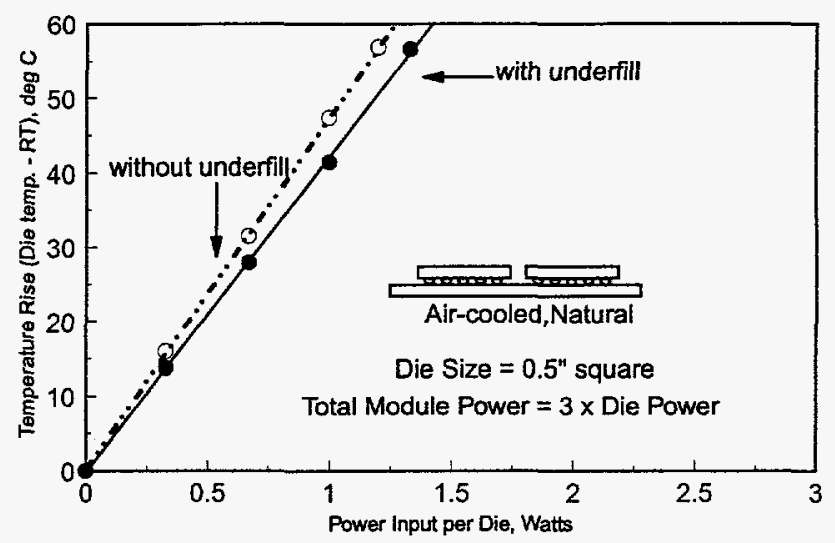

Figure 7. Thermal performance of $\mathrm{mBGA}$ die assemblies on FR-4 board with and without HYSOL 4511 underfill encapsulant.

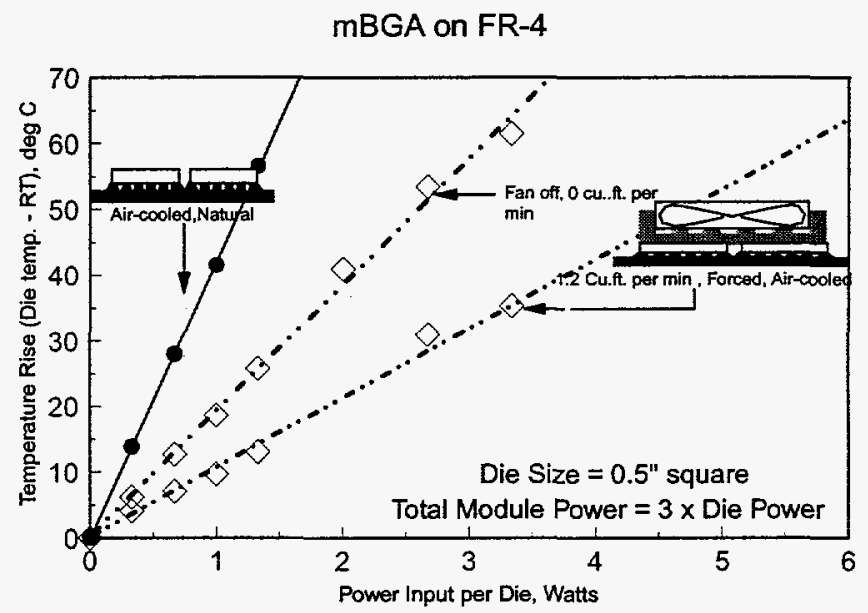

Figure 8. Thermal performance of underfilled mBGA assemblies on FR-4 with and without heatsink.

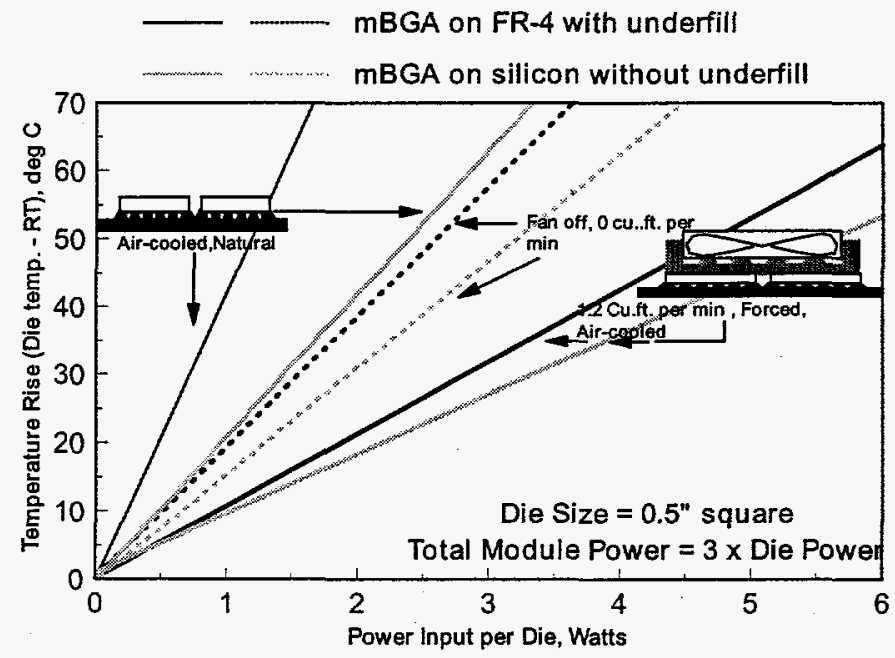

Figure 9. Comparison of thermal performance of mBGA assemblies on FR-4 and on silicon substrate. 